\title{
Inorganic nanoparticles and the microbiome
}

\author{
Kunyu Qiu, Phillip G. Durham ${ }^{\S}$ and Aaron C. Anselmo ( $\left.\varangle\right)$ \\ Division of Pharmacoengineering and Molecular Pharmaceutics, Eshelman School of Pharmacy, University of North Carolina at \\ Chapel Hill, Chapel Hill, NC 27599, USA

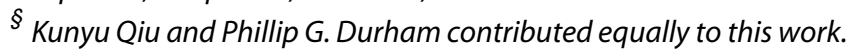

Received: 7 April 2018

Revised: 17 June 2018

Accepted: 22 June 2018

(C) Tsinghua University Press and Springer-Verlag GmbH Germany, part of Springer

Nature 2018

\section{KEYWORDS}

inorganic nanoparticles, microbiota, microbiome, bacteria, metals

\begin{abstract}
Routine exposure to inorganic nanoparticles (NPs) that are incorporated into consumer products such as foods/drinks, packaging materials, pharmaceuticals, and personal care products (e.g. cosmetics, sunscreens, shampoos) occurs on a daily basis. The standard everyday use of these products facilitates interactions between the incorporated inorganic NPs, mammalian tissues (e.g. skin, gastrointestinal tract, oral cavity), and the community of microbes that resides on these tissues. Changes to the microbiome have been linked to the initiation/ progression of many diseases and there is a growing interest focused on understanding how inorganic NPs can initiate these changes. As these mechanisms are revealed and defined, it may be possible to rationally design microbiotamodulating therapies based on inorganic NPs. In this article, we will: (i) provide a background on inorganic NPs that are commonly found in consumer products such as those that incorporate titanium, zinc, silver, silica, or iron, (ii) discuss how NP properties, microbiota composition, and the physiological microenvironment can mediate the effects that inorganic NPs have on the microbiota, and (iii) highlight opportunities for inorganic NP therapies that are designed to interact with, and navigate, the microbiome.
\end{abstract}

\section{Introduction}

The human body must coexist and form cooperative relationships with microbial communities, including bacteria, archaea, viruses, and fungi [1]. These communities are commonly referred to as the microbiota or as the microbiome, when their genetic material is included. Compositional changes to the microbiota, often resulting from interactions with foreign materials [2, 3], have been linked to microbiota imbalance, and termed dysbiosis [4]. Dysbiosis is widely studied for its role in diseases [5] such as diabetes [6], irritable bowel disease [7], and colon cancer [8], to name a few. One of the most studied open questions in this domain is whether dysbiosis is a cause or an effect of these diseases [9]. In either case, dysbiosis is a major concern as it can potentially play a role in the initiation or progression of diseases; as such, there is significant interest in understanding how, why, and when dysbiosis occurs. 
New microbes and foreign materials are introduced to the microbiome through ingestion, physical contact, and/or respiration, which can initiate dramatic compositional changes, including dysbiosis [2, 3, 10-13]. This is especially relevant for microbiomes that are exposed to the environment (e.g., gastrointestinal (GI) tract [14], skin [15], oral cavity [16], and airway [17]). As such, many consumer products (e.g., foods, pharmaceuticals, and personal care products) and their individual components can directly influence these microbiomes [18, 19]. Inorganic nanoparticles (NPs) are commonly found in a vast number of consumer products that interact with our skin, GI tract, and mucus membranes [19, 20], and thus have the potential to cause unintentional changes to the microbiome (Fig. 1). While it is known that inorganic NPs can influence microbial fate and function when used as antibacterial agents [21, 22], limited number of studies have examined the effect of inorganic NPs

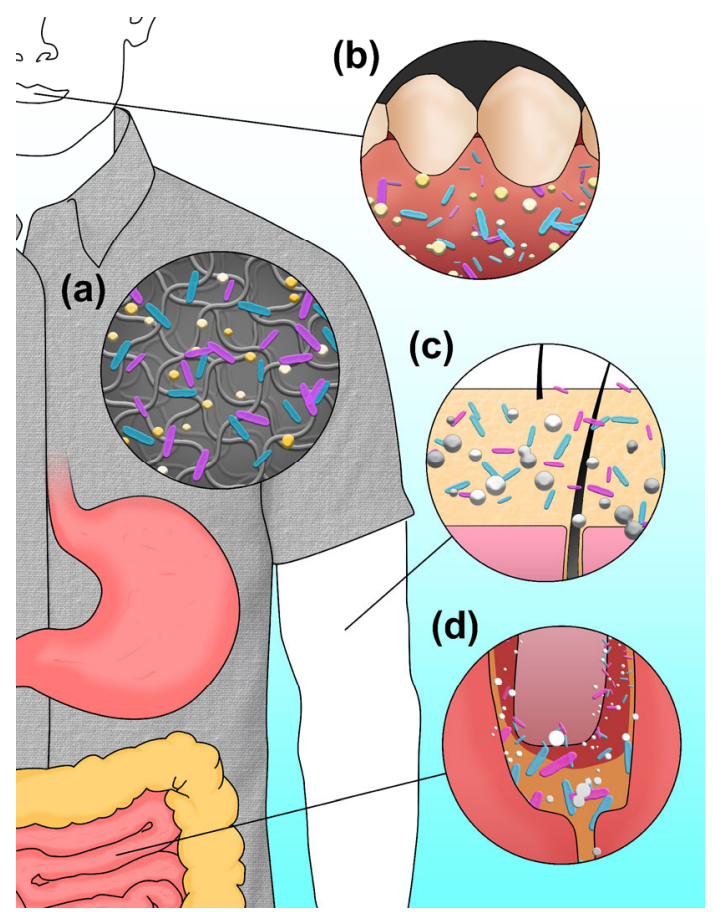

Figure 1 Inorganic NPs contained in consumer products can interact with the local microbiome. (a) Silver NPs, which are, at times, included in the clothing fabric to reduce the bacterial odor associated with sweating, can interact with our skin microbiome. (b) $\mathrm{TiO}_{2} \mathrm{NPs}$, included as a whitening agent in toothpastes, can interact with the oral microbiome. (c) $\mathrm{ZnO} \mathrm{NPs}$, included in sunscreen products as a coloring agent, can interact with the skin microbiome. (d) $\mathrm{SiO}_{2} \mathrm{NPs}$, often used as a bulking agent in foods and pharmaceuticals, can interact with the GI microbiome. on non-pathogenic commensal microbial populations and their potential implications on microbiome health [23].

This review will focus on describing the role of inorganic NPs, especially those that are encountered in everyday life, in shaping and influencing commensal microbiota. Detailed discussion on the advantages, utility, and widespread use of NPs in the pharmaceutical, food, cosmetic, and other consumer products is beyond the scope of this review, because these details have been extensively reviewed previously [20, 24, 25]. Here, we specifically highlight (i) the inorganic nanomaterials that are commonly used in consumer products (Fig. 2), (ii) the studies that have investigated the interactions between these inorganic NPs and commensal microbiota, and (iii) the potential opportunities for the development of inorganic NP-based therapeutics for the microbiome.

\section{Inorganic NPs}

Inorganic NPs possess unique physical properties based on their size, surface plasmon resonance, and inorganic element content [26, 27]. As such, inorganic NPs find utility in many applications, ranging from the semiconductor industry [28] to the energy sector [26] to the medical field [29], as well as in countless commercial products $[26,30,31]$. Here, we will discuss inorganic NPs (titanium dioxide $\left(\mathrm{TiO}_{2}\right)$, silver $(\mathrm{Ag})$, zinc oxide $(\mathrm{ZnO})$, iron (Fe), and silicon dioxide $\left(\mathrm{SiO}_{2}\right)$ ) (Fig. 2) that are most commonly used in commercial products, such as supplements, foods, pharmaceuticals, and personal care products (e.g., sunscreen and toothpaste). For each of the inorganic NPs discussed here, we will highlight their unique features, the history of their antibacterial properties, and the effect of their use in commercial products on our microbiome.

\subsection{Titanium dioxide}

$\mathrm{TiO}_{2}$ is a naturally occurring metal oxide that exhibits unique ultraviolet absorption, photocatalytic, and dielectric properties, especially in the form of NPs [32, 33]. Millions of tons of $\mathrm{TiO}_{2}$ are produced every year; it can be manufactured in a range of particle sizes via hydrothermal, chemical vapor deposition, and sol-gel 
approaches [33-35]. $\mathrm{TiO}_{2}$ is used as a component in many consumer products, as a whitening agent or pigment. Some examples of $\mathrm{TiO}_{2}$-containing products that can potentially interact with our microbiome include paints, foods (Fig. 2(a)) [30], pharmaceuticals, cosmetics, and personal care products (e.g., sunscreen and toothpaste) [30,36]. Estimates state that some individuals ingest up to $3 \mathrm{mg}$ of $\mathrm{TiO}_{2} \mathrm{NPs}$ per kilogram of bodyweight per day [30]. As such, the widely known antibacterial properties of $\mathrm{TiO}_{2}$, which were described over 30 years ago [37], represents a potential concern for our commensal microbiota. In the seminal paper describing these antibacterial properties, $\mathrm{TiO}_{2} / \mathrm{Pt}$ NPs were shown to be toxic to both gram-positive and gram-negative bacteria, commonly found in our GI tract, during exposure to high-intensity broadband light [37]. It was later shown that the antibacterial properties of $\mathrm{TiO}_{2} \mathrm{NPs}$ can also occur under exposure to ultraviolet [38] and visible light [39]; these toxic effects are exerted against the microbes commonly found on our skin (e.g., Staphylococcus aureus (S. aureus) [40] and Streptococcus pyogenes [40]) and GI tract (e.g., Escherichia coli (E. coli) and Aeromonas hydrophila [41]). The proposed mechanism underlying $\mathrm{TiO}_{2} \mathrm{NP}$ photocatalytic-mediated toxicity involves generation of reactive oxygen species (ROS) such as $\mathrm{H}_{2} \mathrm{O}_{2}$ and hydroxyl radicals, which degrade bacterial cell walls or cytoplasmic membranes [42]. These photocatalytic toxic effects have been reviewed in detail [43]. Importantly, $\mathrm{TiO}_{2} \mathrm{NP}$ exposure in our GI tract occurs under dark conditions, and thus, in the absence of both light and photocatalytic activity, which significantly deviates from the majority of the previous work in this area. However, recent studies suggest that $\mathrm{TiO}_{2}$ NPs exhibit toxicity against commensal intestinal microbes such as lactobacilli, enterobacteria, and Acetobacter species, in the absence of light [44].

\subsection{Silver}

$\mathrm{Ag}$ is an elemental metal that is (i) the highest conductive metal for both electricity and heat and (ii) the most reflective metal [45]. Many methods to manufacture Ag NPs have been developed, such as electroreduction of metal salts [46], sonodecomposition [47], and microwave treatment [48]. The medical (a)

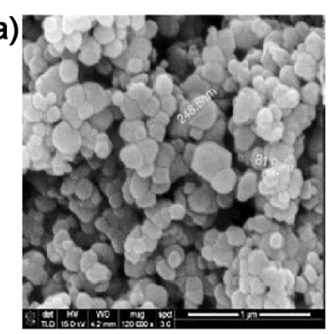

Titanium dioxide NPs:

Skin: Paints, cosmetics, sunscreen

GI: Foods, pharmaceuticals Oral: Toothpaste

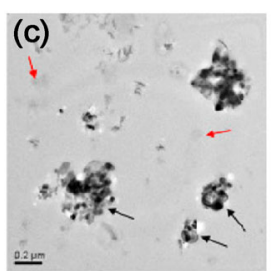

Zinc oxide NPs:

Skin: Calamine lotion, shampoo, sunscreen GI: Foods, pharmaceuticals Oral: Toothpaste

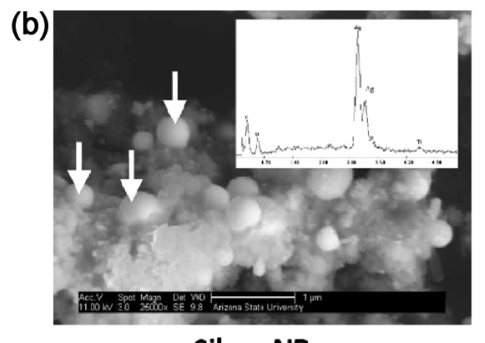

Silver NPs:

Skin: Topical antiseptic, clothing, disinfectants

GI: Food packaging, pharmaceuticals
Figure 2 Inorganic NPs in consumer products. Inorganic NPs are utilized in a variety of consumer products, as listed here: (a) titanium dioxide (food grade, E171; 1,000 nm scale bar) (adapted with permission from Ref. [30], (C) American Chemical Society 2012), (b) silver (Fox River (Xstatic) sock; 1,000 nm scale bar) (adapted with permission from Ref. [31], (C) American Chemical Society 2008), (c) zinc oxide (sunscreen sourced from the USA; $200 \mathrm{~nm}$ scale bar) (reprinted with permission from Ref. [62], (C) Elsevier 2015), (d) iron (oral diagnostic ferumoxsil/GastroMARK $\AA$; $50 \mathrm{~nm}$ scale bar) (reprinted with permission from Ref. [77], (C) Elsevier 1995), and (e) silicon dioxide (food additive, synthetic amorphous silica (Evonik); $100 \mathrm{~nm}$ scale bar) (adapted with permission from Ref. [90], (C) American Chemical Society 2012).

applications of $\mathrm{Ag}$, including its use in blood purifiers or for preventing bad breath, date back to the 700s [49]. Since as early as the 1800s, it was widely accepted that food and drinks stored in Ag vessels exhibited enhanced shelf life [49]. Ag NPs were first reported for use as a wound antiseptic in 1891, by the surgeon B.C. Crede [50]. In modern times, Ag NPs are used as antibacterials in oral/topical medications, clothing fabric (Fig. 2(b)) [31], disinfectants, and foods/food packaging materials [51]. Interestingly, it has been shown that the Ag NPs incorporated in both clothing fabric [31] and food packaging material [52] can be released from the material and introduced into our drinking water or food. Both bulk Ag ions, which can 
be released from Ag NPs, and Ag NPs themselves exhibit antibacterial properties, with the antibacterial mechanism underlying the action of the bulk Ag ions believed to be the inhibition of essential enzymatic functions through direct interactions with the enzyme thiol groups [53]. For Ag NPs, it is believed that the accumulation of NPs at the cell membrane, and subsequent infiltration into the intracellular compartments, leads to the loss of membrane integrity and disruption of cell function [54]. The direct effects of Ag NPs on pathogenic bacteria for medicinal use have been extensively reviewed [54, 55], and therefore, will not be discussed further. Many individual interactions between Ag NPs and commensal microbes have also been described. For example, Ag NPs were shown to be highly toxic against common commensal microbes (Lactobacillus bulgaricus (L. bulgaricus) and Lactobacillus casei (L. casei)), while exhibiting less toxicity against pathogenic microbes (E. coli and S. aureus) [56]. This study, among others [57, 58], point to a complex relationship that is dependent on the properties of Ag NP as well as on individual bacteria.

\subsection{Zinc oxide}

$\mathrm{ZnO}$ is a metal oxide that is often utilized in the NP form, given its antibacterial properties and "generally regarded as safe" status [59]. Over 1.5 million tons of $\mathrm{ZnO}$ are manufactured for commercial purposes every year, mostly via pyrometallurgical or hydrometallurgical methods [60, 61]. ZnO NPs are used as a whitening or brightening agent in foods, pharmaceuticals, supplements, cosmetics, and personal care products (e.g., calamine lotion, sunscreens (Fig. 2(c)) [62], shampoos, and toothpastes) [19, 61, 63]. ZnO NPs come in contact with our microbiome through different entry routes. The antibacterial properties of $\mathrm{ZnO}$ were described as early as 1928, when it was shown that pure $\mathrm{ZnO}$ and formulated $\mathrm{ZnO}$ (pressed into tablets and likely containing ZnO NPs) exhibited antibacterial properties against common skin microbes [64]. The proposed mechanisms underlying $\mathrm{ZnO}$ NP-induced toxicity include the generation of ROS [65], reorganization of bacterial surface lipids/proteins [66] possibly due to electrostatic interactions [59], and dissociation and release of individual $\mathrm{Zn}$ metal cations
[67]. The antibacterial properties of $\mathrm{ZnO} \mathrm{NP}$ can be controlled according to particle size [68], preparation method [69], and configuration when assembled in films [70]. These antibacterial properties have typically been viewed as exclusively beneficial, as the commercial use of ZnO NPs is generally related to the prevention of bacterial growth.

\subsection{Iron}

Fe is one of the most abundant elements on earth, and it can be synthesized or manufactured into NPs by a variety of physical (e.g., milling), chemical (e.g., reduction-based), or biological methods [71, 72]. Fe is used in various consumer products, including food supplements [73] and food pigments (E172) [74], paint [75], or cosmetic products [76], often as NPs [19]. Iron oxide NPs exhibit unique superparamagnetic properties that enable its use as an FDA-approved oral diagnostic contrast agent (Fig. 2(d)) [77, 78]. Thus, Fe NPs can encounter our microbiome during routine diagnostics. Fe ions can be easily absorbed by our body and they can negatively impact bacteria in different ways (e.g., cell death [79] and morphological changes [80]). As with other metal oxides, Fe ions diffuse into the bacteria and induce the production of toxic ROS [79, 81]. Fe NPs have been shown to be toxic to many commensal bacteria, including E. coli [81], S. aureus [82], and Bacillus subtilis (B. subtilis)[83]. It has also been shown that the size [84], redox state [80], and concentration [80] of Fe NPs influence bacterial fate. Unlike other inorganic elements, Fe ions are known to enhance the growth and proliferation of many microbes, as it is an element essential for their survival [85-87]. These interactions between Fe ions and bacteria are important because Fe NPs readily release Fe ions [88].

\subsection{Silicon dioxide}

Elemental silicon often takes the form of $\mathrm{SiO}_{2}$ or silica, which is a naturally occurring metal oxide. Many advantages related to the physicochemical properties of $\mathrm{SiO}_{2} \mathrm{NP}$ (e.g., porosity, surface chemistry, and size [89]) enable their utility in a variety of commercial applications. Specific examples of commercial products wherein $\mathrm{SiO}_{2}$ NPs interact with our microbiome 
include (i) in the food industry (used as the food additive E551 (Fig. 2(e)) [90] in Europe) [91], for reducing turbidity in beer [92] or for use in wine as a flocculant [93], and as anticaking agents [94]; (ii) as excipients in the pharmaceutical industry for oral and topical medications [95]; and (iii) as a hydrophobic modifier for sunscreen formulations [96]. Some estimates indicate that the daily consumption of $\mathrm{SiO}_{2}$ NPs can be as high as $120 \mathrm{mg}$ [97]. Majority of the studies reporting the antibacterial properties of $\mathrm{SiO}_{2}$ NPs utilize them as delivery vehicles, for the loading and controlled released of chemical-based antibacterials [98-100]. Other commercial examples describe the use of $\mathrm{SiO}_{2}$ mesoporous scaffolds for loading antiseptics in food packaging materials [101]. Similar to the other inorganic NPs discussed, ROS can be induced by $\mathrm{SiO}_{2} \mathrm{NPs}$, which can cause bacterial toxicity [102]. One study reported that $\mathrm{SiO}_{2} \mathrm{NPs}$, compared to bulk (e.g., non-nano) $\mathrm{SiO}_{2}$, increased the inhibition of both commensal (E. coli and B. subtilis) and pathogenic (Pseudomonas fluorescens) microbes by more than two folds; this study highlighted how the unique properties of $\mathrm{SiO}_{2}$, arising at the nanoscale, can cause bacterial toxicity [103]. An in vivo study in mice investigated how $10 \mathrm{~nm} \mathrm{SiO}{ }_{2} \mathrm{NPs}$ altered the intestinal microbiota composition in humans following daily oral ingestion of an estimated dose. An almost two-fold increase was noted in the ratio of the Firmicutes/Bacteroidetes population (FBR) because of $\mathrm{SiO}_{2} \mathrm{NP}$ exposure [104]; this increase in the FBR ratio has been associated with obesity [105].

\section{Evaluating the effect of exposure to inorganic nanoparticles on the microbiome}

Many studies investigating inorganic NP-microbiota interactions focused on the application of bacterial isolates in non-physiologically relevant conditions. Studies that expose inorganic NPs to multiple bacterial species (present as a consortium of commensal microbes) under physiological conditions are primarily considered in this review because these studies present the potential implications of inorganic NP exposure on the microbiome in a more relevant manner. It is essential to note that many of these studies investigating the effects of inorganic NPs on both individual bacteria and bacterial consortia have reported conflicting results. This is not surprising, given that complex factors, such as the model microbiome system or the animal model used, the experimental microenvironment, or the differing physicochemical properties of the NPs all influence microbiota-inorganic NP interactions. Here, we highlight the current state of research in this area, while considering various factors that dictate bacterial response to inorganic NPs.

\subsection{In vitro microbiome models}

In vitro models designed to recreate and study microbiota interactions under specific conditions often reveal insights that may be overshadowed by complex in vivo systems. The main advantage of these in vitro systems is the ability to systematically investigate how single parameters, both related to the NP (e.g., size, shape, concentration, and surface chemistry) or the host (e.g., microbiota composition and physiological conditions) contribute to the outcome. In general, these models make use of a consortium of microbes that are (i) harvested from a living human host and thus can be used to represent patient-specific diseases, or (ii) commercially available and thus offer reproducibility by defining a specific microbial ecosystem. Here, we highlight some of these in vitro models and discuss the useful insights offered by them in understanding and describing inorganic $\mathrm{NP}-$ microbiota interactions.

The commercially available microbial ecosystem therapeutic-1 (MET-1), a well-defined microbial community containing 33 distinct intestinal microbes, was used to test the compositional-shifting effects of two types of food grade $\mathrm{TiO}_{2}$ NPs (E171 and E171-61). Exposure to $\mathrm{TiO}_{2}$ NPs caused statistically significant shifts in the abundance of Bacteroides and Clostridium species. However, phenotypic changes (e.g., production of fatty acids and gases) were not observed in the microbiome. While exposure to food-grade $\mathrm{TiO}_{2} \mathrm{NP}$ induced compositional shifts in the microbiota, these shifts did not translate into measurable physiological changes in the GI tract, and thus did not impact health [106]. A separate study compared the effects of commercial polyvinylpyrrolidone (PVP)-capped Ag NPs and ionic Ag on MET-1 over a period of $48 \mathrm{~h}$ at $37^{\circ} \mathrm{C}$. At all concentrations tested $(25,100$, and 
$200 \mathrm{mg} / \mathrm{mL}$ ), ionic Ag decreased gas production by MET-1, while PVP-Ag NPs induced similar changes only at higher concentrations (100 and $200 \mathrm{mg} / \mathrm{mL}$ ). Furthermore, an approximately two-fold reduction in gas production was observed by ionic $\mathrm{Ag}$, compared to PVP-Ag NPs. In general, gas production is often considered an indicator of bacterial respiration and cell division. Fatty acid profiles were more affected by ionic Ag, compared to PVP-Ag NPs. Changes in fatty acid production have been correlated with the external stress encountered by individual bacteria. $16 \mathrm{~S}$ sequencing revealed that ionic Ag disrupted the phylogenic composition more dramatically, compared to PVP-Ag NPs. These changes were not observed for PVP-only controls, indicating that the polymer coating was not the influencing parameter. While each of these collective Ag-mediated changes were viewed as potentially harmful, it was clear that NP-formulated Ag mitigated many of these negative effects [107]. This study pointed at the advantages that inorganic NPs might exert over their ion counterparts. Inorganic NPs provide a larger surface for coating/encapsulation with PVP or polymers, which might have been one of the driving factors that led to improved tolerability of the NP-formulated Ag by our microbiota, compared to elemental ions.

In a separate study, a host-derived stool sample donated by a healthy 26-year-old female (antibioticfree for 8 months) was exposed to food-grade and industrial-grade $\mathrm{TiO}_{2} \mathrm{NPs}$ in a model colon reactor. This in vitro model was previously developed [108] to simulate weeks of interactions between colonic bacteria, ingested food, and $\mathrm{TiO}_{2} \mathrm{NPs}$ in light-free and anaerobic environmental conditions over a period of 5 days. In this study, the exposure to $\mathrm{TiO}_{2}$ NPs enabled the preservation of Proteobacteria populations (some previous studies have implied that an abundance of Proteobacteria is associated with dysbiosis [109]) and limited the proliferation of Firmicute population, compared to the changes in the control group (not exposed to $\mathrm{TiO}_{2} \mathrm{NP}$ ) [110]. This is one of the first few examples to clearly demonstrate the microbiotamodulating effects of $\mathrm{TiO}_{2} \mathrm{NPs}$ in a simulated model under light-free conditions [110], similar to the conditions in our GI tract. Using the same model, a separate study illustrated that $\mathrm{ZnO} \mathrm{NP}$ exposure initiates a significant decrease in bacterial cell size and lumen $\mathrm{pH}$ over a five-day exposure period. These phenotypic changes in the microbiome implicate stability shifts in the intestinal microenvironment (e.g., size changes indicate morphological changes). $\mathrm{ZnO}$ NPs were exposed to this model system at concentrations designed to mimic the typical environmental exposure from sources such as food or drinking water [111]. One of the most valuable aspects of these studies is that they describe an approach to utilize and evaluate the host-derived microbiome. This system could be expanded to investigate individual responses to inorganic NPs, or to possibly investigate the potential of inorganic NPs in shifting the microbiota composition in a host-derived dysbiotic microbiome for therapeutic applications.

Building on this personalized in vitro microbiome model, while considering that every human has a unique microbiota composition in different tissues, approaches that make use of patient- or host-derived samples can reveal the clinical effects of inorganic NPs. For example, a recent study investigated biofilm inhibition by $\mathrm{ZnO}$ NPs in two separate in vitro models, one grown on epithelial cells, and the other, on polystyrene surfaces. This work leveraged the use of patient-derived microbiome samples isolated from the slurry of a tooth crown surface from a healthy man. ZnO NPs were shown to cause near-complete inhibition of biofilm formation at the highest NP concentrations tested [112]. These initial results can be used as a foundation for future studies with a focus on developing in vitro models to predict the potential therapeutic benefits that inorganic NP-based technologies can offer.

\subsection{Influence of the physiological environment}

The physiological environment serves as the medium for the interactions between inorganic NPs and microbes. This environment is of two-fold importance, because (i) microbes can be sensitized by or can thrive in specific microenvironment conditions (e.g., $\mathrm{pH}$, oxygen concentration, proximity to symbiotic microbes, and nutrient abundance) [113, 114], and (ii) inorganic NPs might exhibit distinct properties (e.g., zeta potential, dissolution rate, and adsorption rate) under different microenvironment conditions (e.g., 
$\mathrm{pH}$ and light exposure) [115] that influence their interactions with cells [116]. For example, the unique chemical environment in the GI tract consists of enzymes, bile, and regions with distinct $\mathrm{pH}$; these factors have been shown to influence the stability as well as the aggregation (and size) of inorganic NPs [115]. In another example, the physical aspects (e.g., mucus barrier, transit time in the GI tract, and unpredictable peristalsis) influence how materials, food, and drugs pass through and interact with our GI tract and the microbiota therein. Understanding the impact of the physical features on inorganic NP transport from the lumen, potentially through mucus, to the bacteria represents a significant knowledge gap. Other gaps exist in the knowledge about inorganic NP-microbiota interactions in diseased conditions (e.g., inflammation) as well as the mechanism by which these distinct conditions in the diseased microenvironment might contribute to the microbiotamodulating effects of the ingested inorganic NPs. Here, we highlight initial studies that identified specific microenvironment conditions mediating inorganic $\mathrm{NP}-$ microbe interactions.

The antibacterial effects of Ag NPs were tested on two commensal strains (L. bulgaricus and L. casei) and two pathogenic strains (E. coli and S. aureus). Both Lactobacillus strains were more susceptible to Ag NPs, compared to the two pathogenic strains. It is proposed that Lactobacillus strains produce lactic acid (Fig. 3(a)) and acidify the local microenvironment (Fig. 3(b)), which rapidly generates Ag ions (Fig. 3(c)) and hydroxyl radicals from the Ag NPs. Generation of Ag ions and hydroxyl radicals promotes intracellular ROS and oxidative stress (Fig. 3(d); green cells), thus increasing cell death (Figs.3(e); red cells). This study clearly outlines how the local $\mathrm{pH}$ microenvironment, as regulated by specific commensal microbes, can create conditions that enhance the antibacterial effects of $\mathrm{Ag}$ NPs [56]. Another study described how $\mathrm{TiO}_{2}$ NPs initiate compositional shifts in the GI microbiota of zebrafish. This work focused on understanding the individual and combined effects of orally doses of $\mathrm{TiO}_{2}$ NPs and bisphenol A (BPA), a chemical used in many canned foods and plastic containers [117]. As such, it is likely that both BPA and $\mathrm{TiO}_{2}$ NPs often encounter the GI microbiome together. The con- centration of BPA in the presence of $\mathrm{TiO}_{2}$ NPs was a defining parameter in reshaping the microbiota (Figs. 3(f) and 3(g)). While $\mathrm{TiO}_{2} \mathrm{NP}$ exposure increased the abundance of Firmicute phylum, the abundance of other phyla (e.g., Cyanobacteria) increased in higher amounts when in the presence of both $\mathrm{TiO}_{2} \mathrm{NPs}$ and BPA. This study highlighted how the presence of other ingested materials can negate or amplify the changes to the microbiota caused by $\mathrm{TiO}_{2}$ NPs [118]; broadly, these efforts could be extended to studying how nutrients, foods, and even drugs might synergistically or antagonistically act with the inorganic NPs in influencing our microbiota.

The in vivo environment, which is exceedingly challenging to mimic and predict in vitro, can also influence the interactions of inorganic NPs with the microbiota. In one case, $\mathrm{TiO}_{2} \mathrm{NPs}$ that were shown to be toxic against lactobacilli, enterobacteria, and Acetobacter species in vitro, did not exert any toxic effects in vivo in Drosophila [44]. While it is not clear which factors lead to these in vitro-in vivo discrepancies, it is possible that they stemmed from limiting physiological conditions (e.g., mucus and transit time) that might have prevented these interactions from occurring as frequently in vivo as they occur under ideal in vitro conditions. Minimal and statistically insignificant changes to the GI microbiota following oral exposure to $\mathrm{TiO}_{2} \mathrm{NPs}$ have also been observed in mice [104]. The intestinal microbiota of male and female zebrafish has been shown to respond differently to oral doses of Ag NPs, wherein exposure to Ag NPs significantly altered the richness and diversity of GI microbiota in male zebrafish, but not in females [119]. In a separate study, $\mathrm{TiO}_{2} \mathrm{NPs}$ initiated differential shifts in the GI microbiota of male and female zebrafish. This study, as previously highlighted, also looked at the combined exposure of $\mathrm{TiO}_{2} \mathrm{NPs}$ and BPA and the differential responses, in both male and female zebrafish (Figs. 3(f) and 3(g)) [118]. Different microbiota-specific responses have been reported in male and female Sprague Dawley rats following oral exposure to Ag NPs, as a function of size and concentration; however, these correlations could not be established and the differences were attributed to initial discrepancies in the genus population in male and female rats [120]. Although it is known that sex 
(a)

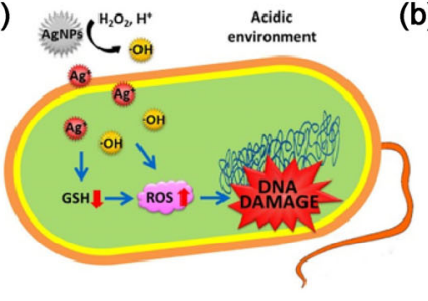

(b)

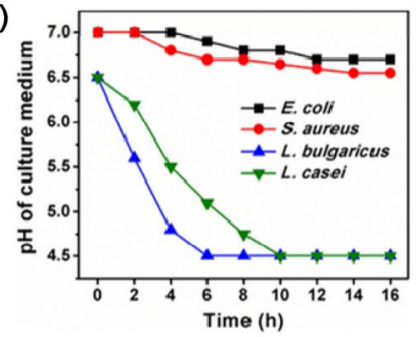

(c)

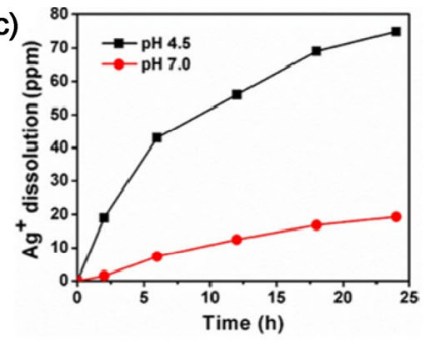

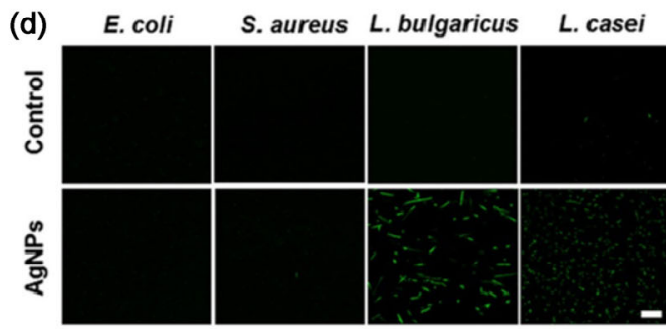

(e)
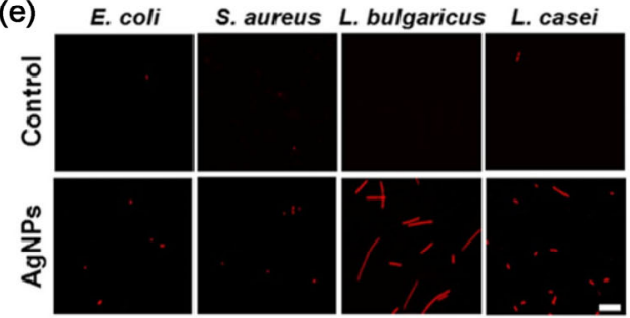

(f)

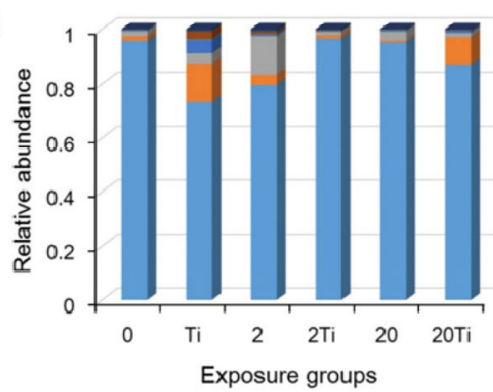

(g)

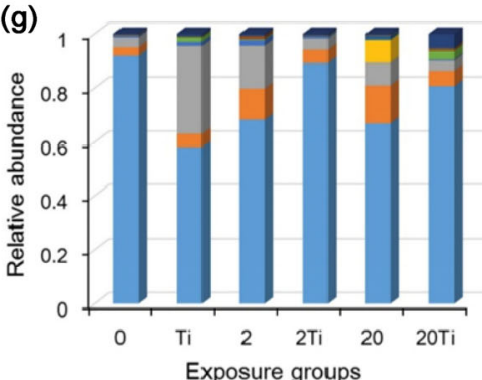

- Proteobacteria

- Firmicutes

- Actinobacteria

nuryarchaeota

n Bacteroidetes

Cyanobacteria

- TM7

- Fusobacteria

- TMG

Acidobacteria

athers

Figure 3 Inorganic NPs influence microbial fate. (a) Proposed mechanism for Ag NP-mediated toxicity against Lactobacillus strains. (b) Changes in the $\mathrm{pH}$ of the culture medium containing bacterial cells, over time. (c) Release of silver ions from Ag NPs as a function of the solution pH. (d) Intracellular ROS and oxidative stress (green; 5-micron scale bar) induced by Ag NP exposure. (e) Cell death (red; 5-micron scale bar) induced by Ag NP exposure. Adapted with permission from Ref. [56], (C) American Chemical Society 2018. Intestinal phylum composition in (f) male and (g) female zebrafish following exposure to $\mathrm{TiO}_{2} \mathrm{NPs}_{\text {and }} \mathrm{BPA}(x$-axis labels; $0=0 \mu \mathrm{g} / \mathrm{L}$ BPA, $0 \mu \mathrm{g} / \mathrm{L} \mathrm{TiO}_{2} ; \mathrm{Ti}=0 \mu \mathrm{g} / \mathrm{L} \mathrm{BPA}, 100 \mu \mathrm{g} / \mathrm{L} \mathrm{TiO}_{2} \mathrm{NP} ; 2=2 \mu \mathrm{g} / \mathrm{L} \mathrm{BPA}, 0 \mu \mathrm{g} / \mathrm{L} \mathrm{TiO}_{2} \mathrm{NP} ; 2 \mathrm{Ti}=2 \mu \mathrm{g} / \mathrm{L} \mathrm{BPA}, 100 \mu \mathrm{g} / \mathrm{L} \mathrm{TiO} \mathrm{NP}_{2} ; 20=$ $20 \mu \mathrm{g} / \mathrm{L} \mathrm{BPA}, 0 \mu \mathrm{g} / \mathrm{L} \mathrm{TiO}_{2} \mathrm{NP} ; 20 \mathrm{Ti}=20 \mu \mathrm{g} / \mathrm{L} \mathrm{BPA}, 100 \mu \mathrm{g} / \mathrm{L} \mathrm{TiO}_{2} \mathrm{NP}$ ) (reprinted with permission from Ref. [118], (C) Elsevier 2018).

can play an important role in dictating microbiotaspecific responses and composition [121,122] it is necessary to invest efforts into understanding the mechanisms underlying the effect of sex on the response to inorganic NPs.

\subsection{Influence of nanoparticle properties}

Many studies have investigated how the properties of inorganic NPs, for example, their size [68], shape [123], coating [124], and elemental composition [125], influence their antibacterial properties. Particular focus has been placed on FBR because an increase in this ratio has been associated with obesity [105]. Here, we highlight studies that investigated how NP properties can impact the microbiota in vivo.
An in vivo study in mice reported that Ag NPs $(12 \mathrm{~nm} ;-12 \mathrm{mV})$ can cause shifts in the GI microbiota. Over two-fold reduction in the FBR was observed following oral exposure to Ag NPs in mice (Fig. 4(a)) [104]. In contrast to these findings, a separate study in mice showed that the oral administration of 55-nm PVP-coated Ag NPs increased the FBR in a dosedependent manner (Fig. 4(b)) [126]. Distinct from these two studies, no significant shifts were observed in the FBR in mice following the administration of $\mathrm{Ag}$ NPs of distinct sizes (20 or $110 \mathrm{~nm}$ ) and coatings (PVP or citrate) (Fig. 4(c)) [127]. This work agreed in principle (no statistical differences in the FBR) with the results of a study using Sprague Dawley rats (both male and female) by using increasing concentrations (up to 
$9 \mathrm{mg} /(\mathrm{kg}$-day) for 28 days) of Ag NP (PVP-coated; $14 \mathrm{~nm}$ ) [128]. A fourth study, using a Sprague Dawley rat model showed that both size and concentration of the gavaged Ag NPs influenced changes in the FBR. In this study, up to $36 \mathrm{mg} / \mathrm{kg}$ Ag NPs (10, 75, and $110 \mathrm{~nm}$ ) was administered daily for 13 weeks, a much longer time than that considered in the previous studies. No general conclusions could be drawn in terms of the contribution of particle size, concentration, and rat sex to the modifications to the FBR; in some groups, the FBR decreased as the particle size increased and vice versa (Fig. 4(d)) [120].

Considering the collective results of these five studies, the complexities and differences related to the properties of NPs, existing microbiota, sex, and perhaps even species play distinct roles in the response of microbiota communities to inorganic NP challenges. It is essential to consider how the experimental differences (e.g., dosing duration and animal feed source), and most importantly, the differences between NP properties, can result in such contrasting results. Moving forward, studies must focus on systematically determining the key factors that influence the toxicity of inorganic NPs against bacteria in physiologically relevant conditions. It is possible that the previously described in vitro systems are a starting point for mechanistic studies. If the underlying mechanisms can be elucidated, it might be possible to engineer therapeutic systems based on inorganic NPs for the treatment of microbiome disorders.

\section{Therapeutic opportunities}

While the key factors and mechanisms governing inorganic NP-mediated changes to the microbiota remain unknown, there exist opportunities that (a)

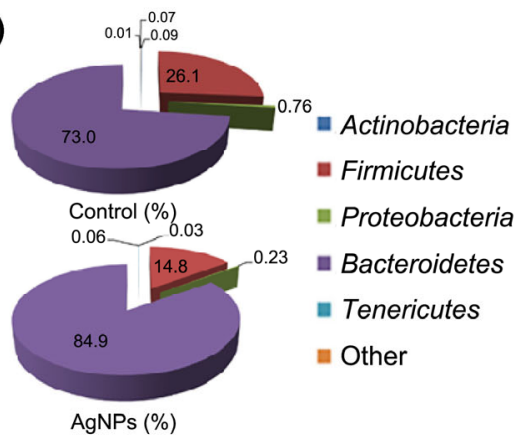

(c) $4.7 \% 1.3 \%$
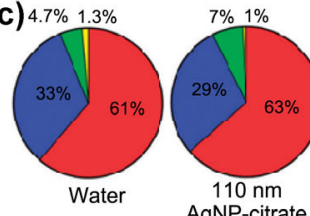
AgNP-citrate

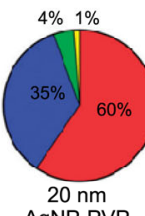

AgNP-PVP

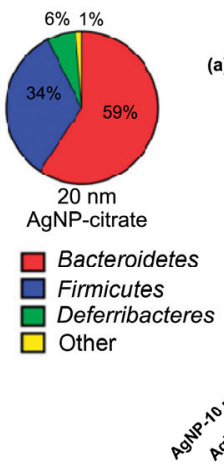

(b)

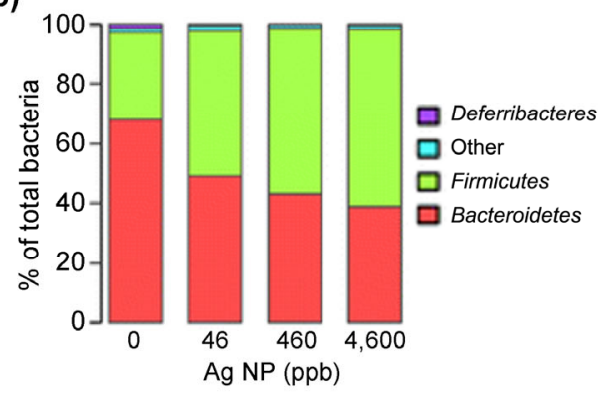

(d)
Proportion of Firmicutes and Bacteroidetes in male rats (a) $100 \%$

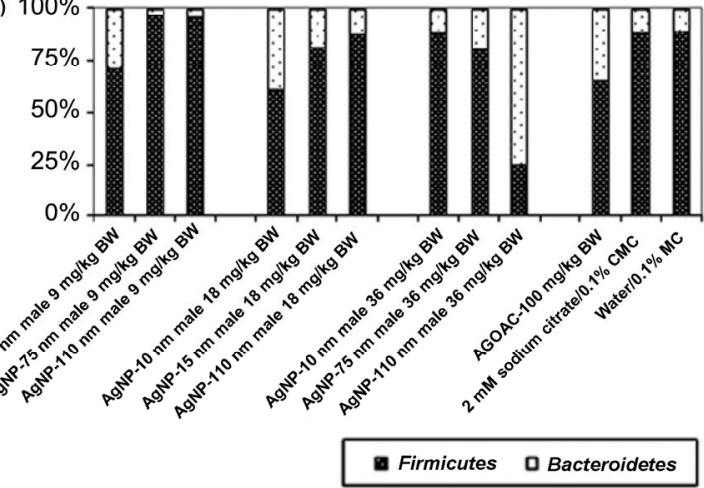

Figure 4 Microbiota modulation in response to Ag NPs. (a) Changes to the bacteria phyla following oral administration of Ag NPs to mice, over 7 days (reprinted with permission from Ref. [104], (C) Elsevier 2017). (b) Abundance of phyla following oral administration of PVP-Ag NPs to mice, over 14 days (adapted with permission from Ref. [126] under the terms of the Creative Commons Attribution 4.0 International License, (C) The Authors 2015). (c) Abundance of bacteria phyla in the cecum following oral administration of PVPand citrate-Ag NPs to rats, over 28 days (reproduced with permission from Ref. [127], (C) Taylor \& Francis Ltd. 2016). (d) FBR following the administration of differently sized Ag NPs at various concentrations to rats, over 13 weeks (reproduced with permission from Ref. [120], (C) Taylor \& Francis Ltd. 2015). 
leverage inorganic NP-microbiota interactions. The broad-spectrum antibacterial properties of inorganic NPs are well known and have been exploited for the non-specific treatment of bacterial infections [21, 22, 129]; as such, these examples were not included here. Instead, we highlight recent examples of therapeutic inorganic NPs that consider the commensal microbiota involved in their therapeutic approach and highlight potential microbiome-related concerns in using inorganic NPs as therapeutics.

\subsection{Formulations to limit microbiota interactions}

Inorganic elements are often used as supplements/ fortificants [130] or as feed additives in the animal husbandry industry [131]. This is especially true for the inorganic elements that are also necessary for life in the form of micronutrients/minerals (e.g., iron and zinc) [132]. One potential application of inorganic NPs is their use as an alternative to the traditional non-nano forms of zinc or iron fortification in an effort to shield or minimize premature interactions between free inorganic ions and the microbiota. This could be accomplished by leveraging a previously highlighted strategy wherein polymer-coated inorganic NPs were shown to interact and influence the microbiota in ways distinct from those employed by their uncoated and non-NP counterparts [107, 127]. There is already an established precedence for this approach wherein NPs coated with polymers or targeting moieties are used to direct the delivery of cargos to specific cells, while avoiding interactions with non-target cells [133]. In this case, inorganic NPs might offer a vehicle to limit premature interactions between the micronutrients and unintended microbiota populations.

Recent work in mice highlighted that oral supplementation with bulk iron sulfate initiated dramatic shifts in microbial composition [134], especially when compared to systemic (i.e., intravenous) iron administration [135]. Given that certain bacteria use iron as a source of food [85-87], and that intravenously administered iron does not interact with the GI microbiota unlike orally administered iron, this is expected. Studies in humans have revealed that bulk iron ingested for fortification increased the populations of enterobacteria and pathogenic E. coli and decreased that of bifidobacteria, which led to intestinal inflammation [136]. Another study reported similar results: Oral iron increased the virulence of already present enteric pathogens [137]. Because of these negative effects related to free iron-microbiota interactions, the use of NP iron or encapsulated iron is currently being investigated in fortification applications to avoid these unintended interactions $[19,138]$. In a recent study, iron NPs (iron hydroxide-adipate tartrate) and iron sulfate were directly compared in humans for their bioavailability and effect on the microbiota. It was shown that the iron from the NPs was absorbed $\sim 80 \%$ as efficiently as the iron from iron sulfate. Supplementation with iron NPs promoted diverse and healthy microbiota, allowing significant increase in the Lactobacillus populations, compared to bulk iron [139]. In a follow up study, iron NPs, compared to iron salt, were less available to the GI microbiota. The authors arrived at this conclusion by comparing the diversity of the microbiota in iron-weaned rats that were supplemented with either iron salt or iron NPs. In the former case, statistically significant changes were observed in the microbiota composition, whereas no statistically significant differences were noted in the iron NP group [140]. These results generally agreed with those of the previous study wherein iron NPs altered the microbiota to a lesser extent. This might resent an exciting approach to deliver supplementary iron without causing toxicity or compositional changes to the microbiota.

In a separate application, bulk $\mathrm{ZnO}$ was used in the food/husbandry industry to mitigate diarrhea and improve the growth of weaning piglets [141, 142]. One study investigated the effect on the microbiota when $\mathrm{ZnO}$ NPs were delivered, instead of standard bulk $\mathrm{ZnO}$, to weaning piglets. This study directly compared how $600 \mathrm{mg} / \mathrm{kg}$ ZnO NPs performed against $2,000 \mathrm{mg} / \mathrm{kg}$ bulk $\mathrm{ZnO}$ over a total of 14 doses. Both $\mathrm{ZnO}$ formulations reduced the incidence of diarrhea associated with weaning; however, bulk $\mathrm{ZnO}$ reduced diarrhea incidence by approximately two folds more. This could possibly be attributed to the greater than three-fold higher dose of bulk $\mathrm{ZnO}$. The microbiota composition (at both phylum and family levels) of all treated groups as a function of intestinal location (i.e., 
ileum, cecum, and colon) was reported (Fig. 5). It was demonstrated that the bacterial diversity increased in the ileum for the ZnO NP groups, but decreased in the cecum and colon. It is this could be because of the slower release of $\mathrm{ZnO}$ from the $\mathrm{ZnO} \mathrm{NPs}$, compared to bulk $\mathrm{ZnO}$, which is already in its free form [143]. These two examples highlight how inorganic NPs can change the interaction between the microbiota and inorganic element-based fortificants or supplements, compared to the non-NP free forms. These encapsulated NP systems can shield the microbiota from the free dissolved Fe or $\mathrm{Zn}$ ions and potentially limit negative inorganic NP-microbiota interactions.

\subsection{Targeted approaches to treat microbial infections}

Rationally designed inorganic NPs have been widely used for numerous biomedical applications [22, 26, $29,144,145]$, and their preclinical success has led to their use in clinical settings [146-148]. As previously highlighted, there are many long-standing examples of the use of inorganic NPs to treat bacterial infections [21, 22]; however, an overwhelming majority of these approaches do not consider the commensal microbiota, as they are not exclusively selective towards pathogens, and as such, function as broad-spectrum antibacterials. It should be noted that the majority of current clinical approaches to treat GI infections typically rely on broad-spectrum antibiotics as the primary therapy [149], which can lead to the evolution of antibioticresistant strains [150] or other grave issues [151]. Alternative therapies, which are currently being investigated in clinical trials, such as fecal microbiota transplants [152] or oral delivery of bacterial spores [153] also rely on broad-spectrum antibiotics to prime the intestinal tissues for spore or microbe delivery. Because the mechanism of action responsible for the efficacy of these cutting-edge approaches is not known, there remains a significant interest in developing approaches to treat the bacterial infections by inhibiting or killing the known pathogens. With growing concerns about the potential damage caused to commensal microbes and the effect of this damage on disease occurrence, there is a growing need to develop technologies that can selectively eliminate pathogenic microbes, without harming healthy commensal microbes.

The majority of inorganic NP-based approaches to treat infections either (i) act as broad-spectrum antibacterials or (ii) rely on using the NPs as delivery
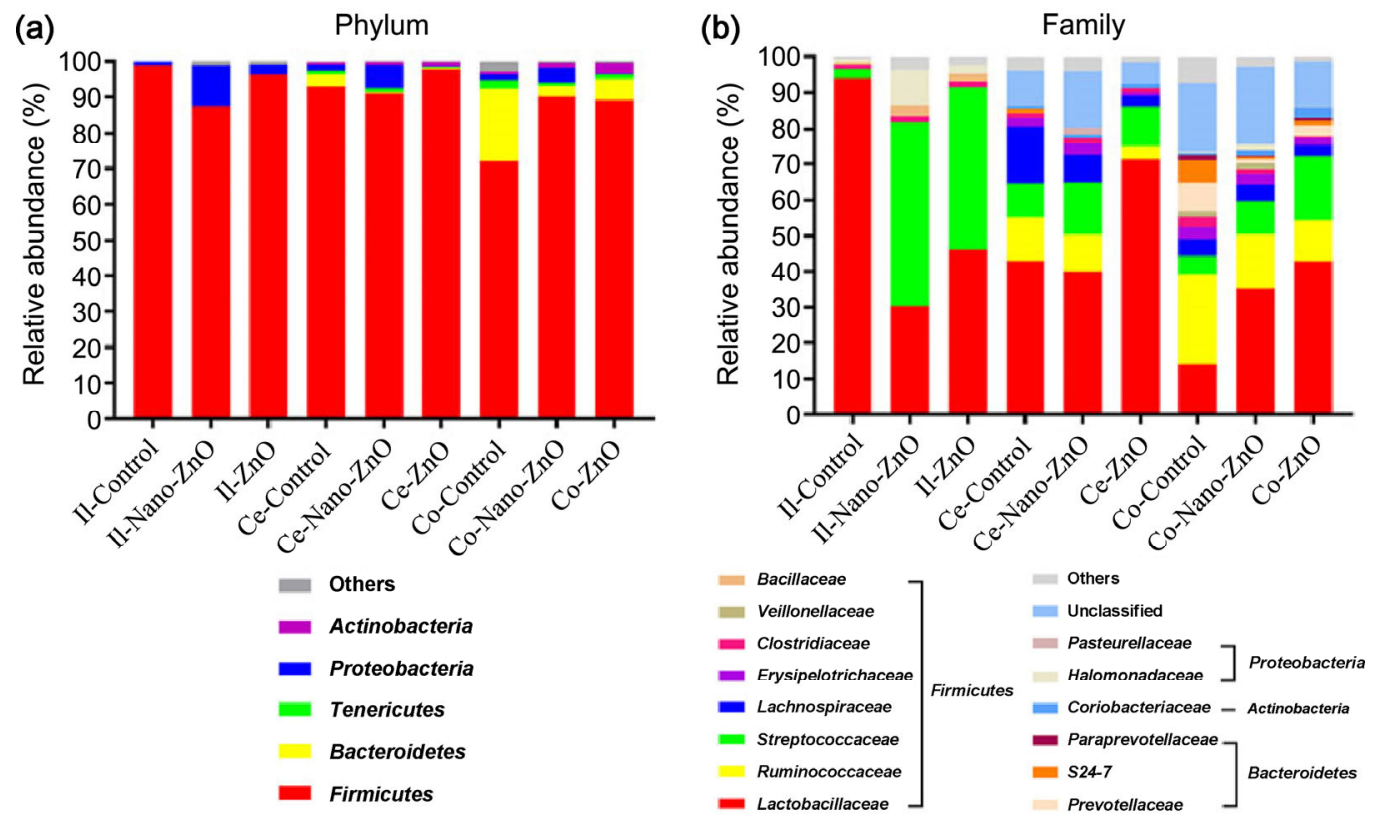

Figure 5 Spatial microbiota modulation in response to ZnO NPs. Microbiota shifts in the (a) phylum and (b) family, following ZnO and $\mathrm{ZnO}$ NP exposure to pigs, over 14 days (Il = ileum; $\mathrm{Ce}=$ cecum; Co $=$ colon) (reproduced with permission from Ref. [143] under a Creative Commons Attribution 3.0 License, (C) The Authors 2017). 
vehicles for the loading and controlled release of chemical-based broad-spectrum antibacterials [98-100]. However, there are recent examples of developed inorganic NPs that can target and selectively kill specific microbes. As such, inorganic NPs can potentially address the above-discussed challenges, including issues related to generating antibiotic-resistant strains. An approach that leveraged the Ag NPs conjugated to selective cell wall-binding domains against either Bacillus anthracis or S. aureus demonstrated that selective targeting and killing of those bacteria could be achieved. This approach offered a modular design wherein the cell wall-binding domains were interchangeable. In three separate examples, the authors showed that $\mathrm{Ag}$ NPs could selectively target and kill (i) B. anthracis in the presence of $B$. subtilis, (ii) B. anthracis in the presence of $S$. aureus, or (iii) $S$. aureus in the presence of $B$. anthracis when the appropriate cell wall-binding domains were used [154]. It is possible that this approach could be extended to more complex microbial communities where the target bacteria may be one species of hundreds, or thousands, of distinct microbes.

Another example utilized pathogen-template silica shells with embedded gold NPs, termed colloid antibodies, to enable selective binding to and killing of the templated pathogen via laser irradiation. Briefly, the pathogen-specific colloid antibodies were generated as follows: (i) A model pathogen was chosen; in this case, it was the yeast Saccharomyces cerevisiae (S. cerevisiae), (ii) the surface of the pathogen was sequentially adsorbed with (a) gold NPs and (b) silica shells, (iii) the coated inorganic shells were fragmented, (iv) the organic matter (e.g., cells and proteins) was removed, and (v) the final pathogen-templated colloid antibodies were purified (Fig. 6(a)). The purified colloid antibodies were shaped such that they specifically bind to the surface of the chosen, and previously templated, pathogen. Upon binding, pathogen-specific killing was achieved by local heating of the colloid antibodies during laser irradiation (Fig. 6(b)). The specificity of this mechanism was confirmed by incubating the colloid antibodies with both the chosen pathogen and the commensal bacterium B. subtilis prior to laser irradiation. It was demonstrated that the selective killing of the model pathogen S. cerevisiae could be achieved with minimal toxicity to the commensal bacterium B. subtilis (Fig. 6(c)) [155]. Utilizing inorganic NPs along with more traditional approaches (e.g., antibiotics) to synergistically enhance the treatment against antibiotic-resistant bacterial infections might be possible; indeed, Ag NPs have been shown to enhance the efficacy of certain antibiotics [156].

\subsection{Microbiome-related concerns: Horizontal gene transfer}

One possible concern related to the use of inorganic NPs as a therapeutic agent lies in their potential to promote horizontal gene transfer and facilitate the spread of drug-resistant properties between bacteria. Alumina NPs could promote horizontal gene transfer of multidrug-resistance via the RP4 plasmid from E. coli to Salmonella. Bulk alumina did not facilitate

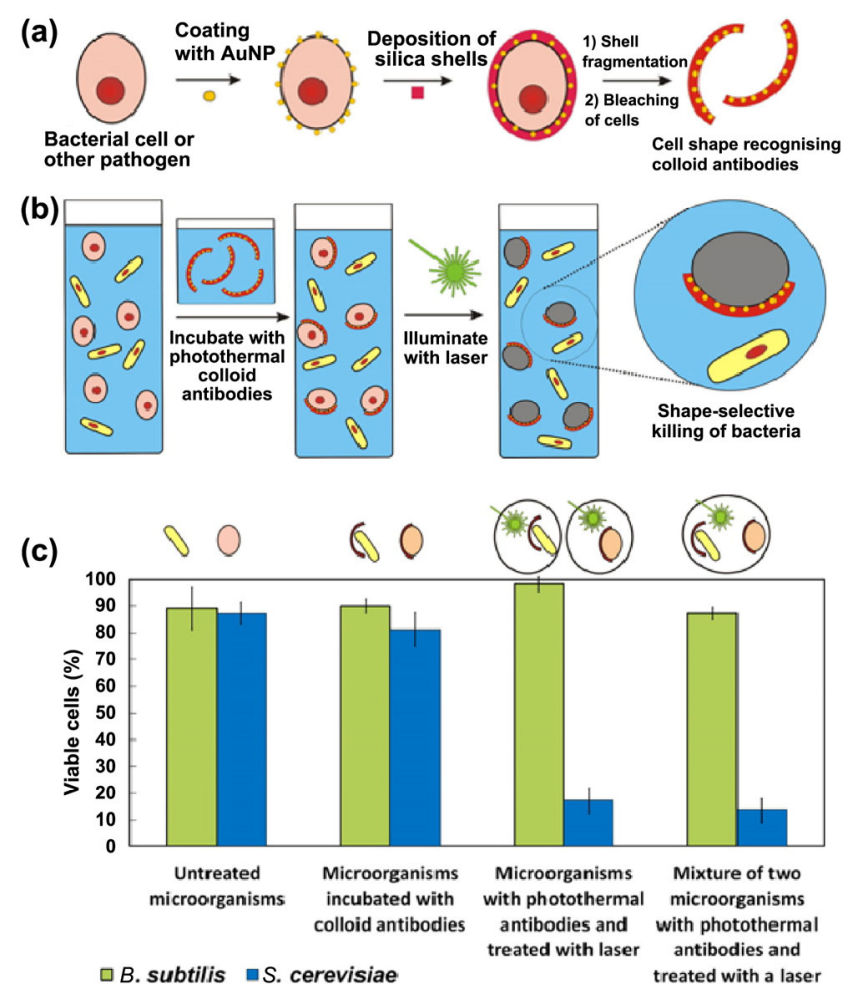

Figure 6 Inorganic particles for pathogen-specific targeting and killing. (a) Method and approach for synthesizing pathogen-specific colloid antibodies. (b) Schematic illustration of selective binding and killing of pathogenic microbes by colloid antibodies, while sparing non-target microbes. (c) Percentage of viable target pathogens ( $S$. cerevisiae) and non-target commensal microbes (B. subtilis) after exposure to various combinations of colloid antibodies and light irradiation. Reprinted with permission from Ref. [155], (C) American Chemical Society 2013. 
horizontal gene transfer, indicating that this may be an NP-specific phenomenon [157]. Similar results were observed with $\mathrm{ZnO}$ NPs, wherein antibiotic-resistant genes were transferred from $E$. coli to many aquatic bacterial genera, including Salmonella, Aeromonas, and Pseudomonas. Controls with bulk $\mathrm{ZnO}$ highlighted that the horizontal gene transfer of antibiotic-resistant genes was again an NP-specific phenomenon [158]. These studies showed how inorganic NPs can facilitate the horizontal transfer of genes that are unwanted in the host microbiome (e.g., multidrug resistance and antibiotic resistance). Future development of inorganic NP-based therapeutics for microbial infections should investigate how the design of NPs and the existing microbiota, which would be a source of genetic material for horizontal transfer, influence NP-mediated horizontal gene transfer.

\section{Conclusion}

Inorganic NPs constitute an example of an entity that is considered safe for human cells, but whose effect on the human microbiome is less understood. As we continue to elucidate the importance of microbiota composition and define a healthy microbial balance, we should consider how inorganic NPs in commercial products affect the body's ecosystem. While current studies provide conflicting evidence, the general take-home message is clear: Inorganic NPs influence our microbiome and shape our microbiota. Many factors, including NP properties, microbiota composition, and physiological microenvironment, govern the extent and intensity of microbiota-modulating effects. Fortunately, advanced in vitro models are being developed and used to mitigate the differences in experimental conditions, which should enable systematic investigations to define the mechanisms underlying the effect of inorganic NPs on microbiota. Inorganic NPs can also provide certain advantages over standard antibiotic-based approaches in the treatment of bacterial infections by leveraging NPspecific features, such as surface functionalization (e.g., polymer coatings and targeting moieties). In other therapeutic applications, optimization of absorption and minimization of unfavorable microbiota interactions with inorganic fortificants (e.g., iron and zinc) can be achieved by developing approaches to control ion release by tuning NP solubility. Despite this, many open questions remain about how therapeutic inorganic NPs can negatively affect the commensal microbiota. For example, current evidence shows that exposure to inorganic NPs can sensitize commensal microbes to horizontal gene transfer where commensal microbes develop resistance to antibiotics. Overall, a common and significant knowledge gap with respect to both inorganic NPs used in commercial products and inorganic NPs used for therapeutic applications is that little is known about how these inorganic NPs influence commensal microbes. Future efforts should focus on addressing this knowledge gap in two ways: (i) by working to understand how inorganic NPs that are currently used in commercial products affect our commensal microbiota, and (ii) by considering the importance of our microbiome as new technologies and applications of inorganic NPs are being developed.

\section{References}

[1] The Human Microbiome Project Consortium. Structure, function and diversity of the healthy human microbiome. Nature 2012, 486, 207-214.

[2] Gibson, G. R.; Roberfroid, M. B. Dietary modulation of the human colonic microbiota: Introducing the concept of prebiotics. J. Nutr. 1995, 125, 1401-1412.

[3] Ubeda, C.; Pamer, E. G. Antibiotics, microbiota, and immune defense. Trends Immunol. 2012, 33, 459-466.

[4] Belizário, J. E.; Napolitano, M. Human microbiomes and their roles in dysbiosis, common diseases, and novel therapeutic approaches. Front. Microbiol. 2015, 6, 1050.

[5] Carding, S.; Verbeke, K.; Vipond, D. T.; Corfe, B. M.; Owen, L. J. Dysbiosis of the gut microbiota in disease. Microb. Ecol. Health Dis. 2015, 26, 26191.

[6] Wen, L.; Ley, R. E.; Volchkov, P. Y.; Stranges, P. B.; Avanesyan, L.; Stonebraker, A. C.; Hu, C. Y.; Wong, F. S.; Szot, G. L.; Bluestone, J. A. et al. Innate immunity and intestinal microbiota in the development of Type 1 diabetes. Nature 2008, 455, 1109-1113.

[7] Manichanh, C.; Borruel, N.; Casellas, F.; Guarner, F. The gut microbiota in IBD. Nat. Rev. Gastroenterol. Hepatol. 2012, 9, 599-608.

[8] Sears, C. L.; Garrett, W. S. Microbes, microbiota, and colon cancer. Cell Host Microbe 2014, 15, 317-328.

[9] Chang, C.; Lin, H. Dysbiosis in gastrointestinal disorders. Best Pract. Res. Clin. Gastroenterol. 2016, 30, 3-15. 
[10] Derrien, M.; van Hylckama Vlieg, J. E. T. Fate, activity, and impact of ingested bacteria within the human gut microbiota. Trends Microbiol. 2015, 23, 354-366.

[11] Meadow, J. F.; Bateman, A. C.; Herkert, K. M.; O’Connor, T. K.; Green, J. L. Significant changes in the skin microbiome mediated by the sport of roller derby. PeerJ 2013, 1, e53.

[12] Dickson, R. P.; Huffnagle, G. B. The lung microbiome: New principles for respiratory bacteriology in health and disease. PLoS Pathog. 2015, 11, e1004923.

[13] David, L. A.; Maurice, C. F.; Carmody, R. N.; Gootenberg, D. B.; Button, J. E.; Wolfe, B. E.; Ling, A. V.; Devlin, A. S.; Varma, Y.; Fischbach, M. A. et al. Diet rapidly and reproducibly alters the human gut microbiome. Nature 2014, 505, 559-563.

[14] Arumugam, M.; Raes, J.; Pelletier, E.; Le Paslier, D.; Yamada, T.; Mende, D. R.; Fernandes, G. R.; Tap, J.; Bruls, T.; Batto, J. M. et al. Enterotypes of the human gut microbiome. Nature 2011, 473, 174-180.

[15] Grice, E. A.; Segre, J. A. The skin microbiome. Nat. Rev. Microbiol. 2011, 9, 244-253.

[16] Dewhirst, F. E.; Chen, T.; Izard, J.; Paster, B. J.; Tanner, A. C.; Yu, W.-H.; Lakshmanan, A.; Wade, W. G. The human oral microbiome. J. Bacteriol. 2010, 192, 5002-5017.

[17] Man, W. H.; de Steenhuijsen Piters, W. A. A.; Bogaert, D. The microbiota of the respiratory tract: Gatekeeper to respiratory health. Nat. Rev. Microbiol. 2017, 15, 259-270.

[18] Maier, L.; Pruteanu, M.; Kuhn, M.; Zeller, G.; Telzerow, A.; Anderson, E. E.; Brochado, A. R.; Fernandez, K. C.; Dose, H.; Mori, H. et al. Extensive impact of non-antibiotic drugs on human gut bacteria. Nature 2018, 555, 623-628.

[19] McClements, D. J.; Xiao, H. Is nano safe in foods? Establishing the factors impacting the gastrointestinal fate and toxicity of organic and inorganic food-grade nanoparticles. npj Sci. Food 2017, 1, 6.

[20] Vance, M. E.; Kuiken, T.; Vejerano, E. P.; McGinnis, S. P.; Hochella Jr, M. F.; Rejeski, D.; Hull, M. S. Nanotechnology in the real world: Redeveloping the nanomaterial consumer products inventory. Beilst. J. Nanotechnol. 2015, 6, 1769 1780 .

[21] Hajipour, M. J.; Fromm, K. M.; Ashkarran, A. A.; de Aberasturi, D. J.; de Larramendi, I. R.; Rojo, T.; Serpooshan, V.; Parak, W. J.; Mahmoudi, M. Antibacterial properties of nanoparticles. Trends Biotechnol. 2012, 30, 499-511.

[22] Miller, K. P.; Wang, L.; Benicewicz, B. C.; Decho, A. W. Inorganic nanoparticles engineered to attack bacteria. Chem. Soc. Rev. 2015, 44, 7787-7807.

[23] Bouwmeester, H.; van der Zande, M.; Jepson, M. A. Effects of food-borne nanomaterials on gastrointestinal tissues and microbiota. WIREs Nanomed. Nanobiotechnol. 2018,
10, e1481.

[24] Raj, S.; Jose, S.; Sumod, U. S.; Sabitha, M. Nanotechnology in cosmetics: Opportunities and challenges. J. Pharm. Bioallied Sci. 2012, 4, 186-193.

[25] Cushen, M.; Kerry, J.; Morris, M.; Cruz-Romero, M.; Cummins, E. Nanotechnologies in the food industryRecent developments, risks and regulation. Trends Food Sci. Technol. 2012, 24, 30-46.

[26] Lohse, S. E.; Murphy, C. J. Applications of colloidal inorganic nanoparticles: From medicine to energy. J. Am. Chem. Soc. 2012, 134, 15607-15620.

[27] Auffan, M.; Rose, J.; Bottero, J.-Y.; Lowry, G. V.; Jolivet, J.-P.; Wiesner, M. R. Towards a definition of inorganic nanoparticles from an environmental, health and safety perspective. Nat. Nanotechnol. 2009, 4, 634-641.

[28] Sun, Y.; Rogers, J. A. Inorganic semiconductors for flexible electronics. Adv. Mater. 2007, 19, 1897-1916.

[29] Liong, M.; Lu, J.; Kovochich, M.; Xia, T.; Ruehm, S. G.; Nel, A. E.; Tamanoi, F.; Zink, J. I. Multifunctional inorganic nanoparticles for imaging, targeting, and drug delivery. ACS Nano 2008, 2, 889-896.

[30] Weir, A.; Westerhoff, P.; Fabricius, L.; Hristovski, K.; von Goetz, N. Titanium dioxide nanoparticles in food and personal care products. Environ. Sci. Technol. 2012, 46, 2242-2250.

[31] Benn, T. M.; Westerhoff, P. Nanoparticle silver released into water from commercially available sock fabrics. Environ Sci. Technol. 2008, 42, 4133-4139.

[32] Testino, A.; Bellobono, I. R.; Buscaglia, V.; Canevali, C.; D'Arienzo, M.; Polizzi, S.; Scotti, R.; Morazzoni, F. Optimizing the photocatalytic properties of hydrothermal $\mathrm{TiO}_{2}$ by the control of phase composition and particle morphology. A systematic approach. J. Am. Chem. Soc. 2007, 129, 3564-3575.

[33] Mahshid, S.; Askari, M.; Ghamsari, M. S. Synthesis of $\mathrm{TiO}_{2}$ nanoparticles by hydrolysis and peptization of titanium isopropoxide solution. J. Mater. Process. Technol. 2007, 189, 296-300.

[34] Lee, S.; Cho, I.-S.; Lee, J. H.; Kim, D. H.; Kim, D. W.; Kim, J. Y.; Shin, H.; Lee, J.-K.; Jung, H. S.; Park, N.-G. et al. Two-step sol-gel method-based $\mathrm{TiO}_{2}$ nanoparticles with uniform morphology and size for efficient photo-energy conversion devices. Chem. Mater. 2010, 22, 1958-1965.

[35] Bavykin, D. V.; Friedrich, J. M.; Walsh, F. C. Protonated titanates and $\mathrm{TiO}_{2}$ nanostructured materials: Synthesis, properties, and applications. Adv. Mater. 2006, 18, 2807-2824.

[36] Kaida, T.; Kobayashi, K.; Adachi, M.; Suzuki, F. Optical characteristics of titanium oxide interference film and the film laminated with oxides and their applications for cosmetics. J. Cosmet. Sci. 2004, 55, 219-220. 
[37] Matsunaga, T.; Tomoda, R.; Nakajima, T.; Wake, H. Photoelectrochemical sterilization of microbial cells by semiconductor powders. FEMS Microbiol. Lett. 1985, 29, 211-214.

[38] Markowska-Szczupak, A.; Ulfig, K.; Morawski, A. W. The application of titanium dioxide for deactivation of bioparticulates: An overview. Catal. Today 2011, 169, 249-257.

[39] Pelaez, M.; Nolan, N. T.; Pillai, S. C.; Seery, M. K.; Falaras, P.; Kontos, A. G.; Dunlop, P. S. M.; Hamilton, J. W. J.; Byrne, J. A.; O'shea, K. et al. A review on the visible light active titanium dioxide photocatalysts for environmental applications. Appl. Catal. B: Environ. 2012, 125, 331-349.

[40] Wong, M.-S.; Chu, W.-C.; Sun, D.-S.; Huang, H.-S.; Chen, J.-H.; Tsai, P.-J.; Lin, N.-T.; Yu, M.-S.; Hsu, S.-F.; Wang, S.-L. et al. Visible-light-induced bactericidal activity of a nitrogen-doped titanium photocatalyst against human pathogens. Appl. Environ. Microbiol. 2006, 72, 6111-6116.

[41] Tong, T. Z.; Shereef, A.; Wu, J. S.; Binh, C. T. T.; Kelly, J. J.; Gaillard, J.-F.; Gray, K. A. Effects of material morphology on the phototoxicity of nano- $\mathrm{TiO}_{2}$ to bacteria. Environ. Sci. Technol. 2013, 47, 12486-12495.

[42] Foster, H. A.; Ditta, I. B.; Varghese, S.; Steele, A. Photocatalytic disinfection using titanium dioxide: Spectrum and mechanism of antimicrobial activity. Appl. Microbiol. Biotechnol. 2011, 90, 1847-1868.

[43] Maness, P.-C.; Smolinski, S.; Blake, D. M.; Huang, Z.; Wolfrum, E. J.; Jacoby, W. A. Bactericidal activity of photocatalytic $\mathrm{TiO}_{2}$ reaction: Toward an understanding of its killing mechanism. Appl. Environ. Microbiol. 1999, 65, 4094-4098.

[44] Liu, L.-Y.; Sun, L.; Zhong, Z.-T.; Zhu, J.; Song, H.-Y. Effects of titanium dioxide nanoparticles on intestinal commensal bacteria. Nucl. Sci. Techniq. 2016, 27, 5.

[45] Ciner, C. On the long run relationship between gold and silver prices A note. Global Finance J. 2001, 12, 299-303.

[46] Zhu, J. J.; Liao, X. H.; Chen, H.-Y. Electrochemical preparation of silver dendrites in the presence of DNA. Mater. Res. Bull. 2001, 36, 1687-1692.

[47] Salkar, R. A.; Jeevanandam, P.; Aruna, S. T.; Koltypin, Y.; Gedanken, A. The sonochemical preparation of amorphous silver nanoparticles. J. Mater. Chem. 1999, 9, 1333-1335.

[48] Jiang, H. J.; Moon, K.-S.; Zhang, Z. Q.; Pothukuchi, S.; Wong, C. P. Variable frequency microwave synthesis of silver nanoparticles. J. Nanopart. Res. 2006, 8, 117-124.

[49] Alexander, J. W. History of the medical use of silver. Surg. Infect. 2009, 10, 289-292.

[50] Hill, W. R.; Pillsbury, D. M. Argyria: The Pharmacology of Silver; Williams \& Wilkins Company: Baltimore, 1939.
[51] Maillard, J.-Y.; Hartemann, P. Silver as an antimicrobial: Facts and gaps in knowledge. Crit. Rev. Microbiol. 2013, 39, 373-383.

[52] Echegoyen, Y.; Nerín, C. Nanoparticle release from nanosilver antimicrobial food containers. Food Chem. Toxicol. 2013, 62, 16-22.

[53] Matsumura, Y.; Yoshikata, K.; Kunisaki, S.-I.; Tsuchido, T. Mode of bactericidal action of silver zeolite and its comparison with that of silver nitrate. Appl. Environ. Microbiol. 2003, 69, 4278-4281.

[54] Morones, J. R.; Elechiguerra, J. L.; Camacho, A.; Holt, K.; Kouri, J. B.; Ramírez, J. T.; Yacaman, M. J. The bactericidal effect of silver nanoparticles. Nanotechnology 2005, 16, 2346-2353.

[55] Chen, X.; Schluesener, H. Nanosilver: A nanoproduct in medical application. Toxicol. Lett. 2008, 176, 1-12.

[56] Tian, X.; Jiang, X. M.; Welch, C.; Croley, T. R.; Wong, T. Y.; Chen, C.; Fan, S. H.; Chong, Y.; Li, R. B.; Ge, C. C. et al. Bactericidal effects of silver nanoparticles on lactobacilli and the underlying mechanism. ACS Appl. Mater. Interfaces 2018, 10, 8443-8450.

[57] Rai, M.; Yadav, A.; Gade, A. Silver nanoparticles as a new generation of antimicrobials. Biotechnol. Adv. 2009, 27, 76-83.

[58] Kim, J. S.; Kuk, E.; Yu, K. N.; Kim, J. H.; Park, S. J.; Lee, H. J.; Kim, S. H.; Park, Y. K.; Park, Y. H.; Hwang, C. Y. et al. Antimicrobial effects of silver nanoparticles. Nanomedicine 2007, 3, 95-101.

[59] Espitia, P. J. P.; Soares, N. d. F. F.; dos Reis Coimbra, J. S.; de Andrade, N. J.; Cruz, R. S.; Medeiros, E. A. A. Zinc oxide nanoparticles: Synthesis, antimicrobial activity and food packaging applications. Food Bioprocess Technol. 2012, 5, 1447-1464.

[60] Kołodziejczak-Radzimska, A.; Jesionowski, T. Zinc oxide-From synthesis to application: A review. Materials 2014, 7, 2833-2881.

[61] Moezzi, A.; McDonagh, A. M.; Cortie, M. B. Zinc oxide particles: Synthesis, properties and applications. Chem. Eng. J. 2012, 185-186, 1-22.

[62] Lu, P.-J.; Huang, S.-C.; Chen, Y.-P.; Chiueh, L.-C.; Shih, D. Y.-C. Analysis of titanium dioxide and zinc oxide nanoparticles in cosmetics. J. Food Drug Anal. 2015, 23, 587-594.

[63] Frassinetti, S.; Bronzetti, G.; Caltavuturo, L.; Cini, M.; Della Croce, C. The role of zinc in life: A review. J. Environ. Pathol. Toxicol. Oncol. 2006, 25, 597-610.

[64] Haxthausen, H.; Rasch, C. Some remarks on the bactericidal properties of zinc oxide. Bri. J. Dermatol. 1928, 40, 497-501. 
[65] Dwivedi, S.; Wahab, R.; Khan, F.; Mishra, Y. K.; Musarrat, J.; Al-Khedhairy, A. A. Reactive oxygen species mediated bacterial biofilm inhibition via zinc oxide nanoparticles and their statistical determination. PLoS One 2014, 9, e111289.

[66] Liu, Y.; He, L.; Mustapha, A.; Li, H.; Hu, Z. Q.; Lin, M. Antibacterial activities of zinc oxide nanoparticles against Escherichia coli O157:H7. J. Appl. Microbiol. 2009, 107, 1193-1201.

[67] Kasemets, K.; Ivask, A.; Dubourguier, H.-C.; Kahru, A. Toxicity of nanoparticles of $\mathrm{ZnO}, \mathrm{CuO}$ and $\mathrm{TiO}_{2}$ to yeast Saccharomyces cerevisiae. Toxicol. in Vitro 2009, 23, 1116-1122.

[68] Yamamoto, O. Influence of particle size on the antibacterial activity of zinc oxide. Int. J. Inorgan. Mater. 2001, 3, 643-646.

[69] Sawai, J.; Igarashi, H.; Hashimoto, A.; Kokugan, T.; Shimizu, M. Effect of particle size and heating temperature of ceramic powders on antibacterial activity of their slurries. J. Chem. Eng. Japan 1996, 29, 251-256.

[70] Colon, G.; Ward, B. C.; Webster, T. J. Increased osteoblast and decreased Staphylococcus epidermidis functions on nanophase $\mathrm{ZnO}$ and $\mathrm{TiO}_{2}$. J. Biomed. Mater. Res. 2006, 78A, 595-604.

[71] Gupta, A. K.; Gupta, M. Synthesis and surface engineering of iron oxide nanoparticles for biomedical applications. Biomaterials 2005, 26, 3995-4021.

[72] Huber, D. L. Synthesis, properties, and applications of iron nanoparticles. Small 2005, 1, 482-501.

[73] Hurrell, R.; Bothwell, T.; Cook, J. D.; Dary, O.; Davidsson, L.; Fairweather-Tait, S.; Hallberg, L.; Lynch, S.; Rosado, J.; Walter, T. et al. The usefulness of elemental iron for cereal flour fortification: A SUSTAIN Task Force report. Nutrit. Rev. 2002, 60, 391-406.

[74] Tennant, D. R. Screening potential intakes of colour additives used in non-alcoholic beverages. Food Chem. Toxicol. 2008, 46, 1985-1993.

[75] Hradil, D.; Grygar, T.; Hradilová, J.; Bezdička, P. Clay and iron oxide pigments in the history of painting. Appl. Clay Sci. 2003, 22, 223-236.

[76] Forestier, S.; Hansenne, I. Cosmetic composition containing a mixture of metal oxide nanopigments and melanine pigments. U.S. Patent 5,695,747, December 9, 1997.

[77] Jung, C. W.; Jacobs, P. Physical and chemical properties of superparamagnetic iron oxide MR contrast agents: Ferumoxides, ferumoxtran, ferumoxsil. Magn. Reson. Imag. 1995, 13, 661-674.

[78] Wang, Y.-X. J. Superparamagnetic iron oxide based MRI contrast agents: Current status of clinical application. Quant. Imaging Med. Surg. 2011, 1, 35-40.

[79] Dixon, S. J.; Stockwell, B. R. The role of iron and reactive oxygen species in cell death. Nat. Chem. Biol. 2014, 10, 9-17.

[80] Auffan, M.; Achouak, W.; Rose, J.; Roncato, M.-A.; Chanéac, C.; Waite, D. T.; Masion, A.; Woicik, J. C.; Wiesner, M. R.; Bottero, J.-Y. Relation between the redox state of iron-based nanoparticles and their cytotoxicity toward Escherichia coli. Environ. Sci. Technol. 2008, 42, 6730-6735.

[81] Touati, D. Iron and oxidative stress in bacteria. Arch. Biochem. Biophys. 2000, 373, 1-6.

[82] Chatterjee, S.; Bandyopadhyay, A.; Sarkar, K. Effect of iron oxide and gold nanoparticles on bacterial growth leading towards biological application. J. Nanobiotechnol. 2011, 9, 34.

[83] Diao, M. H.; Yao, M. S. Use of zero-valent iron nanoparticles in inactivating microbes. Water Res. 2009, 43, 5243-5251.

[84] Borcherding, J.; Baltrusaitis, J.; Chen, H. H.; Stebounova, L.; Wu, C.-M.; Rubasinghege, G.; Mudunkotuwa, I. A.; Caraballo, J. C.; Zabner, J.; Grassian, V. H. et al. P. Iron oxide nanoparticles induce Pseudomonas aeruginosa growth, induce biofilm formation, and inhibit antimicrobial peptide function. Environ. Sci.: Nano 2014, 1, 123-132.

[85] Ratledge, C.; Dover, L. G. Iron metabolism in pathogenic bacteria. Ann. Rev. Microbiol. 2000, 54, 881-941.

[86] Bullen, J.; Rogers, H. J.; Griffiths, E. Role of iron in bacterial infection. In Current Topics in Microbiology and Immunology; Arber W.; Henle, W.; Hofschneider, P. H.; Humphrey, J. H.; Klein, J.; Koldovský, P.; Koprowski, H.; Maaløe, O.; Melchers, F.; Rott, R. et al., Eds.; Springer: Berlin, Heidelberg, 1978; pp 1-35.

[87] Neilands, J. Iron and its role in microbial physiology. In Microbial Iron Metabolism; Neilands, J. B. Ed.; Elsevier: Amsterdam, 1974; pp 3-34.

[88] Lee, C.; Kim, J. Y.; Lee, W. I.; Nelson, K. L.; Yoon, J.; Sedlak, D. L. Bactericidal effect of zero-valent iron nanoparticles on Escherichia coli. Environ. Sci. Technol. 2008, 42, 4927-4933.

[89] Slowing, I. I.; Vivero-Escoto, J. L.; Wu, C.-W.; Lin, V. S.-Y. Mesoporous silica nanoparticles as controlled release drug delivery and gene transfection carriers. Adv. Drug Delivery Rev. 2008, 60, 1278-1288.

[90] Peters, R.; Kramer, E.; Oomen, A. G.; Herrera Rivera, Z. E.; Oegema, G.; Tromp, P. C.; Fokkink, R.; Rietveld, A.; Marvin, H. J.; Weigel, S. et al. Presence of nano-sized silica during in vitro digestion of foods containing silica as a food additive. ACS Nano 2012, 6, 2441-2451.

[91] Fruijtier-Pölloth, C. The safety of nanostructured synthetic amorphous silica (SAS) as a food additive (E 551). Arch. Toxicol. 2016, 90, 2885-2916.

[92] Ito, M.; Yamamoto, S.; Okada, A.; Ishiwata, Y. Silica gel for stabilization treatment of beer, a method of manufacturing the silica gel and a method of the stabilization treatment of 
beer. U.S. Patent 6,565,905, May 20, 2003.

[93] Mierczynska-Vasilev, A.; Smith, P. Current state of knowledge and challenges in wine clarification. Austr. J. Grape Wine Res. 2015, 21, 615-626.

[94] Villota, R.; Hawkes, J. G.; Cochrane, H. Food applications and the toxicological and nutritional implications of amorphous silicon dioxide. Crit. Rev. Food Sci. Nutr. 1986, 23, 289-321.

[95] Rowe, R. C.; Sheskey, P. J.; Owen, S. C. Handbook of Pharmaceutical Excipients; Pharmaceutical Press: London, 2006.

[96] Hansenne, I.; Rick, D. W. High SPF nontacky/nongreasy UV-photoprotecting compositions comprising particulates of MMA crosspolymers. U.S. Patent 6,432,389, August $13,2002$.

[97] Dekkers, S.; Krystek, P.; Peters, R. J.; Lankveld, D. P.; Bokkers, B. G.; van Hoeven-Arentzen, P. H.; Bouwmeester, H.; Oomen, A. G. Presence and risks of nanosilica in food products. Nanotoxicology 2011, 5, 393-405.

[98] Hetrick, E. M.; Shin, J. H.; Paul, H. S.; Schoenfisch, M. H. Anti-biofilm efficacy of nitric oxide-releasing silica nanoparticles. Biomaterials 2009, 30, 2782-2789.

[99] Trewyn, B. G.; Whitman, C. M.; Lin, V. S.-Y. Morphological control of room-temperature ionic liquid templated mesoporous silica nanoparticles for controlled release of antibacterial agents. Nano Lett. 2004, 4, 2139-2143.

[100] Li, L. L.; Wang, H. Enzyme-coated mesoporous silica nanoparticles as efficient antibacterial agents in vivo. $A d v$. Healthcare Mater. 2013, 2, 1351-1360.

[101] Appendini, P.; Hotchkiss, J. H. Review of antimicrobial food packaging. Innov. Food Sci. Emerg. Technol. 2002, 3, 113-126.

[102] Zhang, W.; Li, Y.; Niu, J. F.; Chen, Y. S. Photogeneration of reactive oxygen species on uncoated silver, gold, nickel, and silicon nanoparticles and their antibacterial effects. Langmuir 2013, 29, 4647-4651.

[103] Jiang, W.; Mashayekhi, H.; Xing, B. S. Bacterial toxicity comparison between nano- and micro-scaled oxide particles. Environ. Pollut. 2009, 157, 1619-1625.

[104] Chen, H. Q.; Zhao, R. F.; Wang, B.; Cai, C. X.; Zheng, L. N.; Wang, H. L.; Wang, M.; Ouyang, H.; Zhou, X. Y.; Chai, Z. F. et al. The effects of orally administered $\mathrm{Ag}, \mathrm{TiO}_{2}$ and $\mathrm{SiO}_{2}$ nanoparticles on gut microbiota composition and colitis induction in mice. NanoImpact 2017, 8, 80-88.

[105] Ley, R. E.; Turnbaugh, P. J.; Klein, S.; Gordon, J. I. Microbial ecology: Human gut microbes associated with obesity. Nature 2006, 444, 1022-1023.

[106] Dudefoi, W.; Moniz, K.; Allen-Vercoe, E.; Ropers, M.-H.; Walker, V. K. Impact of food grade and nano- $\mathrm{TiO}_{2}$ particles on a human intestinal community. Food Chem. Toxicol. 2017, 106, 242-249.

[107] Das, P.; McDonald, J. A.; Petrof, E. O.; Allen-Vercoe, E.; Walker, V. K. Nanosilver-mediated change in human intestinal microbiota. J. Nanomed. Nanotechnol. 2014, 5, 235.

[108] Marcus, I. M.; Wilder, H. A.; Quazi, S. J.; Walker, S. L. Linking microbial community structure to function in representative simulated systems. Appl. Environ. Microbiol. 2013, 79, 2552-2559.

[109] Shin, N.-R.; Whon, T. W.; Bae, J.-W. Proteobacteria: Microbial signature of dysbiosis in gut microbiota. Trends Biotechnol. 2015, 33, 496-503.

[110] Waller, T.; Chen, C.; Walker, S. L. Food and industrial grade titanium dioxide impacts gut microbiota. Environ. Eng. Sci. 2017, 34, 537-550.

[111] Taylor, A. A.; Marcus, I. M.; Guysi, R. L.; Walker, S. L. Metal oxide nanoparticles induce minimal phenotypic changes in a model colon gut microbiota. Environ. Eng. Sci. 2015, 32, 602-612.

[112] Khan, S. T.; Ahamed, M.; Al-Khedhairy, A.; Musarrat, J. Biocidal effect of copper and zinc oxide nanoparticles on human oral microbiome and biofilm formation. Mater. Lett. 2013, 97, 67-70.

[113] Matin, A.; Auger, E. A.; Blum, P. H.; Schultz, J. E. Genetic basis of starvation survival in nondifferentiating bacteria. Ann. Rev. Microbiol. 1989, 43, 293-314.

[114] Cotter, P. D.; Hill, C. Surviving the acid test: Responses of gram-positive bacteria to low pH. Microbiol. Mol. Biol. Rev. 2003, 67, 429-453.

[115] Jones, K.; Morton, J.; Smith, I.; Jurkschat, K.; Harding, A.-H.; Evans, G. Human in vivo and in vitro studies on gastrointestinal absorption of titanium dioxide nanoparticles. Toxicol. Lett. 2015, 233, 95-101.

[116] Verma, A.; Stellacci, F. Effect of surface properties on nanoparticle-cell interactions. Small 2010, 6, 12-21.

[117] Vandenberg, L. N.; Hauser, R.; Marcus, M.; Olea, N.; Welshons, W. V. Human exposure to bisphenol A (BPA). Reproduct. Toxicol. 2007, 24, 139-177.

[118] Chen, L. G.; Guo, Y. Y.; Hu, C. Y.; Lam, P. K. S.; Lam, J. C. W.; Zhou, B. S. Dysbiosis of gut microbiota by chronic coexposure to titanium dioxide nanoparticles and bisphenol A: Implications for host health in zebrafish. Environ. Pollut. 2018, 234, 307-317.

[119] Ma, Y. B.; Song, L. B.; Lei, Y.; Jia, P. P.; Lu, C. J.; Wu, J. F.; Xi, C. W.; Strauss, P.; Pei, D. S. Sex dependent effects of silver nanoparticles on the zebrafish gut microbiota. Environ. Sci.: Nano 2018, 5, 740-751.

[120] Williams, K.; Milner, J.; Boudreau, M. D.; Gokulan, K.; Cerniglia, C. E.; Khare, S. Effects of subchronic exposure 
of silver nanoparticles on intestinal microbiota and gutassociated immune responses in the ileum of SpragueDawley rats. Nanotoxicology 2015, 9, 279-289.

[121] Markle, J. G. M.; Frank, D. N.; Mortin-Toth, S.; Robertson, C. E.; Feazel, L. M.; Rolle-Kampczyk, U.; von Bergen, M.; McCoy, K. D.; Macpherson, A. J.; Danska, J. S. Sex differences in the gut microbiome drive hormone-dependent regulation of autoimmunity. Science 2013, 339, 1084-1088.

[122] Org, E.; Mehrabian, M.; Parks, B. W.; Shipkova, P.; Liu, X. Q.; Drake, T. A.; Lusis, A. J. Sex differences and hormonal effects on gut microbiota composition in mice. Gut Microbes 2016, 7, 313-322.

[123] Pal, S.; Tak, Y. K.; Song, J. M. Does the antibacterial activity of silver nanoparticles depend on the shape of the nanoparticle? A study of the gram-negative bacterium Escherichia coli. Appl. Environ. Microbiol. 2007, 73, 1712-1720.

[124] Kvitek, L.; Panáčk, A.; Soukupová, J.; Kolář, M.; Večeřová, R.; Prucek, R.; Holecová, M.; Zbořil, R. Effect of surfactants and polymers on stability and antibacterial activity of silver nanoparticles (NPs). J. Phys. Chem. C 2008, 112, 5825-5834.

[125] Thiel, J.; Pakstis, L.; Buzby, S.; Raffi, M.; Ni, C.; Pochan, D. E. J.; Shah, S. I. Antibacterial properties of silver-doped titania. Small 2007, 3, 799-803.

[126] van den Brûle, S.; Ambroise, J.; Lecloux, H.; Levard, C.; Soulas, R.; De Temmerman, P.-J.; Palmai-Pallag, M.; Marbaix, E.; Lison, D. Dietary silver nanoparticles can disturb the gut microbiota in mice. Particl. Fibre Toxicol. 2015, 13, 38 .

[127] Wilding, L. A.; Bassis, C. M.; Walacavage, K.; Hashway, S.; Leroueil, P. R.; Morishita, M.; Maynard, A. D.; Philbert, M. A.; Bergin, I. L. Repeated dose (28-day) administration of silver nanoparticles of varied size and coating does not significantly alter the indigenous murine gut microbiome. Nanotoxicology 2016, 10, 513-520.

[128] Hadrup, N.; Loeschner, K.; Bergström, A.; Wilcks, A.; Gao, X. Y.; Vogel, U.; Frandsen, H. L.; Larsen, E. H.; Lam, H. R.; Mortensen, A. Subacute oral toxicity investigation of nanoparticulate and ionic silver in rats. Arch. Toxicol. 2012, 86, 543-551.

[129] Zazo, H.; Colino, C. I.; Lanao, J. M. Current applications of nanoparticles in infectious diseases. J. Control. Release 2016, 224, 86-102.

[130] Acosta, E. Bioavailability of nanoparticles in nutrient and nutraceutical delivery. Curr. Opin. Colloid Interface Sci. 2009, 14, 3-15.

[131] Zhao, C.-Y.; Tan, S.-X.; Xiao, X.-Y.; Qiu, X.-S.; Pan, J.-Q.; Tang, Z.-X. Effects of dietary zinc oxide nanoparticles on growth performance and antioxidative status in broilers. Biolog. Trace Elem. Res. 2014, 160, 361-367.

[132] Black, M. M.; Baqui, A. H.; Zaman, K.; Persson, L. A.; El Arifeen, S.; Le, K.; McNary, S. W.; Parveen, M.; Hamadani, J. D.; Black, R. E. Iron and zinc supplementation promote motor development and exploratory behavior among Bangladeshi infants. Am. J. Clin. Nutr. 2004, 80, 903-910.

[133] Peer, D.; Karp, J. M.; Hong, S.; Farokhzad, O. C.; Margalit, R.; Langer, R. Nanocarriers as an emerging platform for cancer therapy. Nat Nanotechnol 2007, 2, 751-760.

[134] Dostal, A.; Chassard, C.; Hilty, F. M.; Zimmermann, M. B.; Jaeggi, T.; Rossi, S.; Lacroix, C. Iron depletion and repletion with ferrous sulfate or electrolytic iron modifies the composition and metabolic activity of the gut microbiota in rats. J. Nutr. 2012, 142, 271-277.

[135] Werner, T.; Wagner, S. J.; Martínez, I.; Walter, J.; Chang, J.-S.; Clavel, T.; Kisling, S.; Schuemann, K.; Haller, D. Depletion of luminal iron alters the gut microbiota and prevents Crohn's disease-like ileitis. Gut 2011, 60, 325-333.

[136] Jaeggi, T.; Kortman, G. A.; Moretti, D.; Chassard, C.; Holding, P.; Dostal, A.; Boekhorst, J.; Timmerman, H. M.; Swinkels, D. W.; Tjalsma, H. et al. Iron fortification adversely affects the gut microbiome, increases pathogen abundance and induces intestinal inflammation in Kenyan infants. Gut 2015, 64, 731-742.

[137] Kortman, G. A. M.; Boleij, A.; Swinkels, D. W.; Tjalsma, $\mathrm{H}$. Iron availability increases the pathogenic potential of Salmonella typhimurium and other enteric pathogens at the intestinal epithelial interface. PLoS One 2012, 7, e29968.

[138] Zimmermann. The potential of encapsulated iron compounds in food fortification: A review. Int. J. Vitam. Nutr. Res. 2004, 74, 453-461.

[139] Pereira, D. I. A.; Bruggraber, S. F. A.; Faria, N.; Poots, L. K.; Tagmount, M. A.; Aslam, M. F.; Frazer, D. M.; Vulpe, C. D.; Anderson, G. J.; Powell, J. J. Nanoparticulate iron(III) oxo-hydroxide delivers safe iron that is well absorbed and utilised in humans. Nanomed.: Nanotechnol. Biol. Med. 2014, 10, 1877-1886.

[140] Pereira, D. I. A.; Aslam, M. F.; Frazer, D. M.; Schmidt, A.; Walton, G. E.; McCartney, A. L.; Gibson, G. R.; Anderson, G. J.; Powell, J. J. Dietary iron depletion at weaning imprints low microbiome diversity and this is not recovered with oral nano Fe(III). MicrobiologyOpen 2015, 4, 12-27.

[141] Poulsen, H. D. Zinc oxide for weanling piglets. Acta Agricult. Scandin. A-Anim. Sci. 1995, 45, 159-167.

[142] Cho, J. H.; Upadhaya, S. D.; Kim, I. H. Effects of dietary supplementation of modified zinc oxide on growth performance, nutrient digestibility, blood profiles, fecal 
microbial shedding and fecal score in weanling pigs. Anim Sci. J. 2015, 86, 617-623.

[143] Xia, T.; Lai, W. Q.; Han, M. M.; Han, M.; Ma, X.; Zhang, L. Y. Dietary $\mathrm{ZnO}$ nanoparticles alters intestinal microbiota and inflammation response in weaned piglets. Oncotarget 2017, 8, 64878-64891.

[144] Huang, H. C.; Barua, S.; Sharma, G.; Dey, S. K.; Rege, K. Inorganic nanoparticles for cancer imaging and therapy. $J$. Control. Release 2011, 155, 344-357.

[145] Na, H. B.; Song, I. C.; Hyeon, T. Inorganic nanoparticles for MRI contrast agents. Adv. Mater. 2009, 21, 2133-2148.

[146] Anselmo, A. C.; Mitragotri, S. Nanoparticles in the clinic. Bioeng. Transl. Med. 2016, 1, 10-29.

[147] Anselmo, A. C.; Mitragotri, S. A review of clinical translation of inorganic nanoparticles. AAPS J. 2015, 17, 1041-1054.

[148] Mitragotri, S.; Anderson, D. G.; Chen, X. Y.; Chow, E. K.; Ho, D.; Kabanov, A. V.; Karp, J. M.; Kataoka, K.; Mirkin, C. A.; Petrosko, S. H. et al. Accelerating the translation of nanomaterials in biomedicine. ACS Nano 2015, 9, 66446654.

[149] Kohanski, M. A.; Dwyer, D. J.; Collins, J. J. How antibiotics kill bacteria: From targets to networks. Nat. Rev. Microbiol. 2010, 8, 423-435.

[150] Sommer, M. O.; Dantas, G. Antibiotics and the resistant microbiome. Curr. Opin. Microbiol. 2011, 14, 556-563.

[151] Kelly, C. P.; LaMont, J. T. Clostridium difficile-More difficult than ever. N Engl. J. Med. 2008, 359, 1932-1940.

[152] Vargason, A. M.; Anselmo, A. C. Clinical translation of microbe-based therapies: Current clinical landscape and preclinical outlook. Bioeng. Transl. Med., in press, DOI: 10.1002/btm2.10093.

[153] Khanna, S.; Pardi, D. S.; Kelly, C. R.; Kraft, C. S.; Dhere, T.; Henn, M. R.; Lombardo, M. J.; Vulic, M.; Ohsumi, T.; Winkler, J. et al. A Novel microbiome therapeutic increases gut microbial diversity and prevents recurrent Clostridium difficile infection. J. Infect. Dis. 2016, 214, 173-181.

[154] Kim, D.; Kwon, S. J.; Wu, X.; Sauve, J.; Lee, I.; Nam, J.; Kim, J.; Dordick, J. S. Selective killing of pathogenic bacteria by antimicrobial silver nanoparticle-Cell wall binding domain conjugates. ACS Appl. Mater. Interfaces 2018, 10, 13317-13324.

[155] Borovicka, J.; Metheringham, W. J.; Madden, L. A.; Walton, C. D.; Stoyanov, S. D.; Paunov, V. N. Photothermal colloid antibodies for shape-selective recognition and killing of microorganisms. J. Am. Chem. Soc. 2013, 135, 5282-5285.

[156] Shahverdi, A. R.; Fakhimi, A.; Shahverdi, H. R.; Minaian, $\mathrm{S}$. Synthesis and effect of silver nanoparticles on the antibacterial activity of different antibiotics against Staphylococcus aureus and Escherichia coli. Nanomed.: Nanotechnol. Biol. Med. 2007, 3, 168-171.

[157] Qiu, Z. G.; Yu, Y. M.; Chen, Z. L.; Jin, M.; Yang, D.; Zhao, Z. G.; Wang, J. F.; Shen, Z. Q.; Wang, X. W.; Qian, D. et al. Nanoalumina promotes the horizontal transfer of multiresistance genes mediated by plasmids across genera. Proc. Natl. Acad. Sci. USA 2012, 109, 4944-4949.

[158] Wang, X. L.; Yang, F. X.; Zhao, J.; Xu, Y.; Mao, D. Q.; Zhu, X.; Luo, Y.; Alvarez, P. J. J. Bacterial exposure to $\mathrm{ZnO}$ nanoparticles facilitates horizontal transfer of antibiotic resistance genes. NanoImpact 2018, 10, 61-67. 